\title{
Review: nicotine replacement treatments achieve smoking abstinence at 6-12 months
}

Silagy C, Mant D, Fowler G, et al. Nicotine replacement therapy for smoking cessation. Cochrane Database Syst Rev

2000;(2):CD000146 (latest version 19 May 2000).

QUESTION: In people trying to stop smoking, how effective are different nicotine replacement treatments (NRTs) in achieving long term (>6 mo) smoking cessation?

\section{Data sources}

Studies were identified by searching the Cochrane Tobacco Addiction Group specialised register with reference to NRT of any type in the title, abstract, or keywords of trials. The register included the results of searches done in Medline (up to April 2000), PsycLIT (up to March 2000), EMBASE/Excerpta Medica (up to February 1999), and Science Citation Index (up to April 2000).

\section{Study selection}

Studies were selected if they were randomised or quasirandomised controlled trials that compared NRT with placebo or no NRT control, or compared different doses of NRT. Trials had to be $\geqslant 6$ months in duration and include smoking cessation as an outcome measure.

\section{Data extraction}

Data were extracted by 2 independent reviewers on patient characteristics, level of nicotine dependency, presence and level of additional support, methodological quality, NRT type and dosage, and cessation rates.

\section{Main results}

100 trials were identified; 88 trials (34 734 patients) had a non-NRT control group. When trials of all types of NRT were pooled, abstinence rates at 6-12 months of follow up were higher with NRT than with control (table). The pooled abstinence rates for each type of NRT (gum, patch, intranasal spray, inhaler, and sublingual tablet) were also higher than for control (table). The effectiveness of NRT was enhanced with additional support, but did not differ for low or high intensity support. NRT was more effective than control irrespective of the setting in which it was offered. In 3 trials, $4 \mathrm{mg}$ of nicotine gum was more effective than $2 \mathrm{mg}$ among highly dependent smokers (odds ratio [OR] 2.67, 95\% CI 1.69 to 4.22); no effect existed among low dependency or unselected smokers (OR 1.29, CI 0.90 to 1.84). 6 trials showed a benefit from higher doses of patch NRT (OR 1.21 , CI 1.03 to 1.42 ).

\section{Conclusion}

In people trying to quit smoking, nicotine replacement treatments are effective in achieving smoking abstinence at $6-12$ months.
Sources of funding: NHS Research and Development National Cancer Programme and NHS Anglia and Oxford Region Research and Development

Programme.

For correspondence: Dr C Silagy, Monash Medical Centre, Monash Institute of Public Health and Health Services Research, Locked Bag 29, Clayton, Victoria 3168, Australia. Fax $+61395947554$.
Nicotine replacement treatment (NRT) v control (placebo or no NRT) for smoking cessation at 6 to 12 months*

\begin{tabular}{|c|c|c|c|c|c|}
\hline \multirow[b]{2}{*}{ NRT type } & \multirow{2}{*}{$\begin{array}{l}\text { Number } \\
\text { of trials }\end{array}$} & \multicolumn{2}{|c|}{$\begin{array}{l}\text { Weighted event } \\
\text { rates }\end{array}$} & \multirow[b]{2}{*}{ RBI (95\%) } & \multirow[b]{2}{*}{ NNT (CI) } \\
\hline & & NRT & Control & & \\
\hline Total NRT & 88 & $16.4 \%$ & $10.4 \%$ & $56 \%$ (48 to 66 ) & 17 (15 to 19$)$ \\
\hline Nicotine gum & 48 & $17.5 \%$ & $11.6 \%$ & $46 \%$ (36 to 57$)$ & 17 (15 to 21$)$ \\
\hline Nicotine patch & 30 & $13.9 \%$ & $8.3 \%$ & $67 \%$ (51 to 84$)$ & 18 (16 to 22$)$ \\
\hline Intranasal spray & 4 & $23.8 \%$ & $11.8 \%$ & $102 \%$ (49 to 173 ) & $9(6$ to 15$)$ \\
\hline Inhaled nicotine & 4 & $17.2 \%$ & $9.1 \%$ & $90 \%$ (36 to 167$)$ & 13 (9 to 25$)$ \\
\hline Sublingual tablets & 2 & $20.2 \%$ & $12.7 \%$ & $59 \%(6$ to 141$)$ & 14 (8 to 100$)$ \\
\hline
\end{tabular}

*Abbreviations defined in glossary; RBI, NNT, and $\mathrm{Cl}$ calculated from data in article.

\section{COMMENTARY}

Silagy et al conducted an excellent overview of 100 randomised controlled trials using NRT for smoking cessation with at least 6 months of follow up. The major finding that NRT is effective for smoking cessation is consistent with another recent smoking cessation guideline. ${ }^{1}$

NRT has been studied as gum, patch, nasal spray, oral inhaler, and sublingual tablet. NRT relieves smoking withdrawal and assists smokers to "unlearn" the connection between smoking and nicotine self administration. No one type of NRT is clearly superior over another, and the choice of treatment is left to patient preference or perceived need for oral, manual, or habit substitution. A growing number of studies are testing the efficacy of combination treatment (ie, nicotine patch plus bupropion slow release (SR) or nicotine patch plus nicotine inhaler). All such studies use a "quit date," and self help materials or smoking cessation counselling.

Of note, this review does not include bupropion SR, an antidepressant pill that has proved efficacious for smoking cessation. The level of evidence for bupropion SR is similar to that of nicotine nasal spray and nicotine oral inhaler. ${ }^{1}$

For recalcitrant smokers unable to give up smoking despite multiple attempts with adequate drug treatment, the concept of using NRT for "harm reduction" may be helpful. An example of this approach was used in a study providing nicotine inhalers to smokers to reduce, but not eliminate, their smoking. ${ }^{2}$ Further studies are needed to determine if this is a useful approach to reduce the harm from smoking.

In the clinic, I recommend a stepped care approach: (1) instruct patients to use a quit date; (2) if still smoking, use medication plus a quit date; and (3) if still smoking, refer to a comprehensive behavioural programme (with medication) if available, or repeat the combination of medication plus quit date until successful.

Eric C Westman, MD, MHS Duke and Durham VA Medical Centers Durham, North Carolina, USA

1 Treating tobacco use and dependence. Clinical practice guideline. Washington, DC: US Public Health Service, June 2000. http://www.surgeongeneral.gov/tobacco/ defaulthtm

2 Bolliger CT, Zellweger JP, Danielsson T, et al. Smoking reduction with oral nicotine inhalers: double blind, randomised clinical trial of efficacy and safety. BMJ 2000;321:329-33. 